\title{
A Study on the Inheritance of the Miao's Dance in Guizhou
}

\author{
Yanhua $\mathrm{Mu}$ \\ College of Cultural Law \\ Guizhou University of Finance and Economics \\ Guiyang, China
}

\begin{abstract}
As one of the world-dwelling nationalities in Guizhou, Miao Nationality's unique Miao culture, especially the dance art, brings many tourists to Guizhou. Miao's dance is the crystallization of the Miao People's Wisdom and records the original appearance of the Miao People's production and life. With the development and change of the Times, the Miao people's dance has a succession of fault, network social substitution dance social problems. Therefore, it is urgent to study the inheritance task of Miao's dance. Based on the analysis of the characteristics and the existing problems of the Miao-she dance in Guizhou, the author thinks that the combination of the original ecology and the modern stage art, the promotion of the traditional and modern dance of the Miao, and the creation of the Miao's dance with the contemporary choreographer idea;To employ the Miao and the students in the field teaching, the combination of theory and practice to train the Miao minority Dance Heritage team, the State to provide policy support, financial assistance and so on is the important way to inherit the Miao's dance.
\end{abstract}

Keywords—guizhou; the miao minority dance; inheritanceart

\section{INTRODUCTION}

As a multi-ethnic country, the folk dance of China is rich and colorful, gorgeous. Folk dance is the expression form of people's production and life, carrying rich traditional culture, it is the artistic form that the working people of all ethnic groups create in production and life, and also the crystallization of wisdom of all nationalities. Guizhou Province as a national colony, folk dance numerous, 15 were included in the provincial Intangible cultural Heritage List, one of which is the Miao people's dance. China's national folk dance has 41 items are included in the first batch of national Intangible Cultural Heritage List, Miao dance is also in which the number of 126iii-23. Taking the folk dance of Miao nationality in Guizhou Province as an example, it is not only beneficial to protect traditional culture, but also benefit the integration of national culture, so that 56 nationalities coexist harmoniously and develop harmoniously in multicultural culture. China's 55 ethnic minorities, folk dances for the survival of the environment, living customs and different styles of dance form, standing in the splendid art and culture of the forest. As one of the world's ethnic minority culture in Guizhou this land, dancing is a synonym for the Miao people, the dance is the Miao Minority dance Classic. With the change of the Times, the single of the Miao and the different dance forms gradually, and some of the dance types are gradually lost, therefore, it is of practical significance to find the inheritance path of the dance.

\section{The Cultural Connotation of the MiaO NATIONALITY'S DANCE}

As is known to all, Miao is a nation that has experienced many migrations in history, and there are many legends about the legend of the dance, the author's most appreciative of a saying is that in the migration of thorns all over, the young people on the thorn, trample on or even roll out a road for the people to March, and later the Hmong people in order to commemorate these youth, With the advent of the Nayong County dance-rolling mountain beads, this dance popular in the territory. "The dance, also known as ' Step on the door ', Step on the song Hall ', is a man blowing ' in the", while the lower limbs (including hip, knee, ankle) flexible dance as the main characteristics of the traditional folk dance, because of the dance accompaniment and boast from the dance of the name. "[1] The Miao nationality has different life style because of the different distributing area, these life styles have formed different folk customs, the Miao traditional culture disperses, penetrates into the dance of the Chinese, it is the important concept in the traditional culture for the Miao people of different distributing area, the thought mood, the fixed life habit and the ideological belief. The dance art fuses the traditional thought, the homeopathy native folk custom. such as the Golden Pheasant dance as one of the main dance, mainly popular in Danzhai County, where the Miao people and nature rose to fight, spontaneous creation of the Golden Pheasant Dance, the traditional folk dance, drum Dragon Drum Tiger is Guiding County Hsinpu Township Housa Unique one of the Miao dance, here mainly for the saplings, Drum Dragon Drum Tiger The popularity of the dance and saplings worship dragon inseparable. As a typical representative of the Miao folk dance, the Miao-song dance in Guizhou is prominent in music, the Miao people's literary and artistic colors are vividly displayed in the graceful dance, the beautiful costumes and the cheerful dance steps all highlight the Miao people's unique life aesthetic concept and ideological consciousness, which is a kind of exquisite dance art. 


\section{A. The Cultural Nature of the Miao Nationality's Dance}

The Miao Dynasty dance is created directly by the working masses in labor and life, and it can represent the cultural background of a certain historical period of Miao nationality. Such as Nayong County in the territory of the dance--roll Shan Zhu is in order to commemorate the history of the migration in the thorns in the open road of young people, representing the Miao's migration history. It can be said that culture is the characteristics of folk dance, but also different folk dances can be distinguished from each other's important reference. Because of the cultural characteristics of the dance, the society only appeared the folk dance of different styles, and it is suitable for the excellent folk dances have personalized traditional culture spirit. For example, southeast Guizhou Miao-song-carrying Miao People's history of migration, ancestors in the process of migration for fear of people separated, so to blow the wind, burning the bonfire for the command will be gathered together, in order to dispel the cold, people with the melody of the music dance, that is, now the dance of the The Miao's dance is a symbol of the Miao culture.

\section{B. Folk Custom of the Miao Nationality's Dance}

The history of dance can be traced back to the early days of human development, no matter which kind of dance is closely connected with the national activities which the nation prevails. The Miao folk dance is one of Miao nationality's folklore activities; it can get the audience's affection by its vivid image and superb skill. Different national solar terms also have different dances appear, these dances embody the unique culture of each nation. The Miaohe dance in the southeast of Guizhou is generally found in sacrifices weddings, as well as major festivals (cheerful, sister festival, and so on) activities, this and Miao people worship of the same, there is a "The miao has no lu sheng, the festival cold as ice" and "Lu sheng is not sound, grain is not growing" as a proverb.

\section{The Life of the Miao Nationality's Dance}

Because of the different environment of the National folk dance, it has various customs and traditions, which will have a great influence on the style characteristics of folk dance. Such as "Guizhou" a mountain has four seasons, ten different Days "of the unique natural environment, so that Guizhou Buyi, Miao's song and dance although there is the dance, but the style is different. Even the Miao, different Miao branches, the playing and dance methods are not the same."[2]In the course of migration, the Miao ancestors of Danzhai County found their place of residence because of the lead of the Caragana. Out of gratitude and awe of the Golden Pheasant, the local Caragana dance is named for imitating the action of the Golden Pheasant playing, soaring, foraging and so on, plus Danzhai County is located in the southeast of Guizhou, where the peaks and downs of the region, rivers and vertical, Therefore, the main movements of the Miao nationality in southeastern Guizhou are walking, stepping, and bending, tilting, turning, and so on, these dance movements of the Miao nationality in the life of the Hmong dance show incisively and vividly.

\section{PRoblems IN THE DANCE OF The MiaO NATIONALITY}

In recent years, with the emergence of migrant workers, the traditional village to leave the elderly children at home, thus leading to dance inheritance talent fault; Under the background of the great development of modern technology, the emergence of modern media has caused a shock to the traditional dance teaching; people have made mistakes in traditional dance. The development of traditional village tourism has aggravated the commercialization of the Miao nationality and is the problem in the development and inheritance.

\section{A. Serious Commercialization}

The different areas of the Miao's dance with different geographical characteristics, in the current tourism development occupy a very important position. Many areas of the dance for the tourism industry began to get more indepth and expansion of the development, and attracted countless foreign tourists, deepen the visitors to these Miao areas of the understanding and understanding of the dance, this process to a large extent, to promote the Miao nationality, the inheritance and development of the dance. However, the tourism industry in the dissemination of Miao, the dance, driven by the needs of tourism development, there is a close connection between the folk dance and the commercial activities, and the influence of the tourism culture consumption on the control dance, in order to meet the needs of the tourists, the forced improvement and "innovation" of the control dance, gradually lost the original national characteristics. The most typical is the Xijiang thousand households Miao, in order to pursue the benefit maximization, only attracts the visitor eyeball, regardless of the national characteristic, to the traditional "the folk dance" to carry on the adaptation, forces the folk dance to join some business person to think of the fashionable element, causes the dance the nationality and the unique cultural connotation.

\section{B. Misguided Thinking}

There are some incorrect thoughts in the process of the inheritance of the Miao's dance, which leads some people to equate the ritual and the feudal superstition and mislead people to know the real value of the dance. "Chu ke servant throat, meaning 'jump hole', is the large-scale sacrificial event of the Miao nationality, the legend is to commemorate a pair of men and women who die for Love, and later developed into sacrifice ancestors soul."[3]This is the Miao ritual dance. With the development of the society, some people regard the Miao's ritual rites as feudal superstition, which leads to the gradual disappearance of Miao's ritual dance in some areas of Guizhou. Under the background of economic globalization, people have a blind pursuit and claim to the Western culture, and think that the folk dance of China cannot adapt to the pace of the development of the Times, make the folk dance to the popular direction, lose the original national characteristics of the dance, and indirectly lead to the loss of folk dance. As with the Xijiang thousand households Miao to the outside world, the local Miao River 
dance has lost its original taste under the impact of the cultural difference of tourists at home and abroad.

\section{Inheriting the Talent Fault}

In modern times, the way of spreading folk dance is dance teaching, which can give the special charm of traditional dance to the fans of the dance. But at present, under the impact of the commercialization wave, the middleaged and even young adults in the traditional village of Guizhou go out to work, leaving only the elderly and the children at home, the lack of experienced old actor teaching, no training of new performers, this is one of the reasons for the inheritance of the Miao people's dance. Such as "Nayong Miao", the "rolling mountain beads," a small saplings characteristics of the intangible cultural Heritage there is no inheritance of people and silence. [4] The second cause of the transmission of human faults is the emergence of modern media. such as the Southeast Guizhou region network did not appear before the Miao people's social intercourse is through the dance, music, such as the realization of their previous cheerful, who dinner first eat, this one of the love of the dance of the actors will go out to about another one of the flute lovers, they will eventually gather in a specific performance field. And the emergence of modern media, so that people in the southeast of Guizhou can use the network to communicate; they now eat dinner and will watch their own televisions. The third reason is that there are defects in the concept of teaching in colleges and universities, and the teachers who teach them do not really comprehend the connotation of the Miao nationality's ideology and culture and cannot really exert the artistic charm of traditional Miao. These problems caused the Miao to break through the shackles of the secular, so it is difficult to pass on in the society.

As a multi-ethnic country, the folk dance of China has a strong cultural background, rooted in the people's life, and formed a splendid national culture. However, judging from the inheritance of the Miao's in the modern times, we will find that the Miao's dance in the new culture has fallen into the situation of extinction and marginalization. The problems existing in the Miao-song dance make us have to take measures as soon as possible to find its inheritance path, so that the outstanding traditional culture with unique value can stand in the forest of national culture forever.

\section{THE INHERITANCE MEASURES OF THE MiaO NATIONALITY'S TRADITIONAL DANCE}

\section{A. Promoting the Combination of the Original Ecology of the Miao's and Modern Stage}

The social background of the cultural situation has caused a certain degree of impact to the survival and development of the Miao-she-GUI dance in Guizhou, and it has brought the development opportunity for the form creation of the dance. Traditional Miao's folk-dance is the dance form of the Miao people in the process of ethnic migration and festival activities, and it is the dance form of the original ecological dance, which is the combination of the spiritual outlook of the masses and the national culture characteristics, which reflects the life attitude of the Hmong. With the progress of the modern society, the dance forms have diversified development, some people blindly follow the trend, leading to the national character of the Miao and the unique cultural connotation gradually disappear, the river in the Xijiang River to meet the needs of tourists even to the vulgar, popular direction. In order to solve this problem, the Government should call on the people to pay attention to the local traditional dance culture forms, pay attention to the original folk dance of the national characteristics, and the local part of the old artists in accordance with national characteristics of the dance, add the movement of modern dance art, the original ecological and modern stage of the dance form integration. We should improve the inheritance and development of local dance culture.

\section{B. Promoting the Application of Modern Choreographer Concept to the Dance Creation of the Works}

As the modern process accelerates, the content and form of the dance of the Miao people are needed to innovate and adapt to the development of the society. The modern development of traditional Miao-style dance requires inheriting, spreading, innovating and promoting the traditional dance form, which adapts to the development of the contemporary society. The traditional dance art and the modern choreography concept are fused to break the traditional dance forms of the dance, in order to retain the essence of their traditional dancing culture as the basis of creation, into the modern dance movement and aesthetic, from the overall structure of the dance, the performance style embodies the new choreography concept and dance art, To create both the charm of the traditional dance and the modern art style of the dance. In order to promote the innovation and development of the Miao's dance in Guizhou, it is necessary to speed up the combination of the Miao's and modern choreographer's ideas.

\section{Promoting the Development of Realism in the Dance of the Costumes}

In order to understand and grasp the connotation, we should know the theme of the life and the real example of the surrounding. The combination of the Miao's culture and the real life will leave a deep impression on the people and give them the time of the culture. The art of the Miao's handpainting is based on the national spirit of perseverance and hospitality, which fully embodies the ideological and emotional of the Miao culture, and is influenced by the development of the modern society, which makes the form of the folk dance become more and more realistic. In order to promote the form of the Miao's dance to meet the needs of the modern society, the state needs to recall the experienced dance artists who have gone out of work to change dance movements and dance ideas, conform to the demands of the real social development, and gradually improve the dance forms of the dance. 


\section{Promoting the Classical and Modern Coexistence of the Traditional Dance}

Traditional Miao's lu sheng dance is a dance with the connotation of national classics, with the development of society, the life style and folk custom of the Miao people have been gradually connected with the times, which has formed the coexistence of the dance culture and the modern dance style, which embodies the inheritance and development of the traditional dance art by the society. On the other hand, it embodies the inevitable trend of the development of the dance art in the background of social development. The development of the folk-dance of Miao nationality in Guizhou must be based on the traditional culture of the minority nationalities, and in the culture of this strong inclusive container, the continuous innovation of the dance, the dissemination and inheritance of excellent culture. In order to adapt to the development of modernization, the Miao nationality dance must break through the inherent dance concept and develop the diversified dance form. This is not only beneficial to the inheritance and development of the Miao's dance art, but also to promote the exchange and cooperation of the world dance culture.Under the influence of globalization, the people of Miao nationality in Guizhou Province cannot simply and unilaterally pay attention to the inheritance of the National dance culture, but also base on the development trend of the world dance, and make the Miao folk dance to develop in a pluralistic direction.

\section{E. Promoting the Cultivation of the Inheritance Team of Miao's Dance}

Dance is a body language; its essence is cultural connotation. The Miao folk dance is the true portrayal of the Hmong working People's life, the important cultural and artistic expression of the Miao peoples expressing their inner world and praising the good life, and the development of the Miao-style dance forms, which are closely related to the life of the Miao people. Miao's dance is the art treasure of splendid culture in China, its inheritance and development need a certain material basis, so the government at all levels in the distribution areas such as Danzhai County, Guiding County, Nayong County and so on in Guizhou have to set up special funds for the cultural protection of Miao traditional, and include the annual budget, For the inheritance and development of the Miao nationality dance in Guizhou Province, the government should convene a training course for the old actors of the local teaching, and cultivate the fans of the dance. In order to increase the funds for the education of folk dance in schools, colleges and universities should set up the relevant theory courses of the Miao People's dance, employ the Miao's teaching in the field, and cultivate the inheritance team of the Miao-men's dance in the whole country, which can lay a solid foundation for the development and inheritance of.

\section{CONCLUSION}

The cultural connotations formed by the Miao Nationality's migration history and the unique working life style are the soul of the Miao's, and also embody the cohesion of the national thoughts and feelings and spirit, and we only inherit the cultural connotations and national character in the dance of the power, so that we can boldly carry out the artistic innovation. The number of national folk dances in China is difficult to count, which is formed in the evolution and development of the ancient people's working life, and the characteristics of these dances embody the aesthetic concepts and standards of the people of all nationalities. Along with the society unceasing progress, the folk dance also unceasingly innovates the development, the Guizhou Miao nationality dance and so on is more necessary. We have to complete the inheritance task of the Miao nationality in Guizhou, only to deepen the labor life of the Miao people in Guizhou, and to understand their cultural connotations, aesthetic consciousness and ideas, so that the construction and innovation of the Miao's folk-dance can be developed with each passing day and fruitful.

\section{REFERENCES}

[1] Qishing Hong. Investigation and study on the Miao's dance in Guizhou province [D]. Guizhou Normal University, 2014.

[2] Yuntong Dang. On the contemporary inheritance and protection of the folk dance of the Miao nationality in Guizhou [J]. Ethnic studies in Guizhou, 2014, (06): 59-61.

[3] Zhihuai $\mathrm{Pu}$. The Miao nationality sacrificial rites in Guizhou is a throat [J]. Mass literature, 2013 (05): 46-47.

[4] Tiling Wang. The cultural study of the "Rolling Mountain bead" in the Nayong of Miao people [D]. Guizhou University of Nationalities, 2012.

[5] Xiaoyan Li.A study on the saplings of the dance of the Liupanshui in Guizhou Province [D]. Yunnan College of Art, 2017.

[6] Nian Peng. Miao Nationality · April Eight "The Dance of the" "The Chinese People, 2016 (06): 8-9.

[7] Gaofeng Lu, Yinghua Qian. The inheritance and development of the Rongshui of Miao nationality in Guangxi Province [J]. Journal of Liuzhou Vocational and Technical College, 2015,15 (02): 100$102+107$

[8] Jian Sun. The social function and technical analysis of the dance of the Miao nationality in Guangxi--taking Baise Longlin County as an example [J]. Mass literature, 2017 (24): 22-23. 